\title{
Link Program: Evidence from Microfinance Institution in Jordan
}

\author{
Bashar Al-Zu'bi \\ Arab Open University, Jordan \\ bashar324@gmail.com
}

\begin{abstract}
This paper studies and assesses the methodology of the "Link Program", i.e., a process which the owners of micro-enterprises can undergo to help them grow their micro-enterprises into small and medium sized concerns. We evaluated the impact on the performance of micro entrepreneurs as a function of financial and non-financial support provided by a microfinance bank - NMB. The paper established specific criteria for enterprises' graduation, namely: completing 3 loan periods with outstanding credibility and dedication of repayment, continuous profit growth rate obtained as a result of activities (revenue) expansion, formalizing the enterprise by registering it with the government, and generating jobs for local candidates. The paper made use of a sample of 8,000clients who took business loans and had accessed non-financial support provided by the NMB during a period of six to eighteen months. We employed a standard data analysis against graduation criteria and found the "AS IS" non-financial services (counseling and networking) have affected the performance of a few micro and small enterprises; only $13.7 \%$ of NMB's clients grew. Although many micro and small enterprises do not usually grow as would be expected, the result from Jordan is below the international practices which showed that $50 \%$ and $60 \%$ of modern MSE in Latin America and Asia grew from low entrepreneurs. It was therefore concluded that NMB should design and deliver a more comprehensive and innovative non-financial services ("TO BE" approach).
\end{abstract}

Keywords: Entrepreneurship, MSEs, Microfinance, Graduation, criteria, Non-financial support

\section{Introduction}

It is highly recognized that enabling the underprivileged through increasing access to finance for limited income people and those who are living below poverty line is critical for the economic development of any country. Access to finance has the potential to improve living standards and economic security, stabilizing income and stimulating local economic growth. Microfinance is the stipulation of a variety of financial services to the poor and low-income people in order to enable this segment to play a more active role in the economy. These services include appropriately designed credit, insurance, money transfer, and other means of financial services such as electronic payments that help the poor to increase their income level, handle vulnerabilities and improve their living conditions. However, microfinance institutions know that in order to enhance outreach and support sustainability of enterprises, they would have to innovate and provide business owners with opportunities that will lead to improved enterprise both economically and financially. This is an extremely advanced approach to offering financial as well as non-financial support. Furthermore, the delivery of financial and non-financial services designed to enhance capacity of target groups and to ensure the success of their projects will lead to improvements in the repayment rate and will therefore lead to the quality of the loan portfolio.

This is a very timely move as the unemployment and poverty rates continue to present major challenges for the Jordanian Government. Jordanians who are currently living below the national poverty line were estimated to be at $13.3 \%$ according to the latest World Bank figures. The number of poverty pockets increased from 22 to 32, and the yearly poverty gap increased to JD 101 million $^{1}$. Unemployment grew to $18.5 \%$ during the third quarter of 2017, increasing by 3.8 clear points in comparison with the same period in 2016. The unemployment problem is more aggravated among the youth and those who are living in the remote areas. ${ }^{2}$ This situation has come as a result of instability in the region and slow economic growth; the growth rate went down from $8 \%$ in 2008 to less than 3\% since. Furthermore, a growing number of refugees have placed increased pressure on existing infrastructure, putting social services, employment, and very limited natural resources under increased strain. At the same time however, a high percentage of the

${ }^{1}$ The International Financial Crisis and the Labor Market: A Review of the Impact and Policy Responses. ILO, February 21, 2011.

2 Department of Statistics; www.dos.gov.jo; and International Labor Organization 2011, The International Financial Crisis and the Labor

Market: A Review of the Impact and Policy Responses, Geneva, viewed July, 2017. 
Jordanian labor force is operating in the informal sector; official statistics indicated that $50 \%$ of the labor force, or around950,000 workers, are working in this sector ${ }^{3}$ where barriers to entry are low. In Jordan, these micro and small enterprises are generally defined as those that employ four employees or fewer for micro and 25 employees or fewer for small ${ }^{4}$, and have been estimated to account for around two-thirds (65\%) of total private sector non-agricultural employment in the country ${ }^{5}$.

In spite of the importance of MSEs in generating employment in the country, access to formal financial services in Jordan is limited, with only around $24 \%$ of people having a bank account compared to the regional average of $14 \%$ and an average rate in peer economies of around 70\%. MSEs and entrepreneurship are emerging as part of the next generation of solutions for many development issues and job creation. World over, the MSE sector forms a major chunk of any economy ranging from $30 \%$ to $40 \%$ contributing a significant share to national GDPs. In Jordan, MSEs constitute $98 \%$ of all enterprises in the country and employ over $50 \%$ of the Jordanian workforce. However, it should be highlighted that MSEs are not a magic tool for economic growth. Nevertheless, initiatives working to support the entrepreneurial growthespecially MSEs - can promote stability and development in developing countries such as Jordan. Already a number of programs are boosting entrepreneurship in places where economic growth is critically needed. A vital component in any national development strategy should include the supporting of entrepreneurship and smart investments in MSE growth. Unfortunately, these enterprises face numerous challenges to growth, including limited access to finance and a poorly trained workforce. The World Bank's 2012 "Doing Business" report ranked Jordan $106^{\text {th }}$ out of 183 countries in terms of an enabling environment for SMEs.

Microfinance Sector in Jordan: Microfinance sector started its business in Jordan in 1994. The microfinance sector in Jordan has witnessed a strong and stable growth with an annual average increase in outreach of $16 \%$, growing from 200,754 to 357,777 active clients during the period from 2011 to 2015 . The number of borrowers grew by $9.8 \%$ from 325,744 borrowers at the end of $2014^{6}$. Three MFIs continue to drive market growth; those are Micro fund for Women, Tamweelcom and National Microfinance Bank (NMB). The microfinance sector in Jordan has maintained a strong gender focus with more than two-thirds of all clients being women ${ }^{7}$.The only MFI registered as a bank is "NMB" yet it does not receive deposits according to rules imposed by Central Bank of Jordan (CBJ). The MFIs aim is to provide micro and small loans to entrepreneurs. Microfinance loans grew by $21 \%$ in the period 2013 to 2015. The total loan portfolio of the microfinance companies approximated JD 180 million (\$253 million) at the end of 2015 compared to JD 149 million (\$210 million) at the end of 2014. Moreover, the average value of loans increased from JD 650 (\$916) at the end of 2014 to JD 753 (\$1061) at the end of 2015, at a growth rate of $15.8 \%{ }^{8}$.

Given that this sector is credit driven and disallows the taking of deposits, a high percentage of the unbanked population, particularly low-income people, the youth, women and people from remote areas, have been left with limited access to adequate - affordable and needs-based - payments and micro savings products. In the microfinance sector, $69 \%$ of borrowers, $69 \%$ of loans and $67 \%$ of MFI branches are located outside the capitol Amman. The number of borrowers inside Amman grew by 6\% in 2015 compared to 11\% outside of Amman ${ }^{9}$.According to a financial awareness and inclusion questionnaire conducted in Jordan in 2016, $11 \%$ of respondents reported being clients of MFIs while around $40 \%$ of the sample stated to not be aware of microfinance ${ }^{10}$.

AGFUND Initiative: The top priority of The Arab Gulf program for Development (AGFUND) is to treat and control issues related to poverty, and help with its eradication out of the belief that poverty and all its negative consequences are real obstacles to the process of economic and social development. In this perspective, HRH Prince Talal launched his initiative to create "Banks for the Poor" in the least developed

\footnotetext{
${ }^{3} \mathrm{Al}$ Quds Center for Political Study. July 13, 2010.

${ }^{4}$ Ministry of Industry and Trade; www.mit.gov.jo

5Unemployment in Jordan. The European Training Foundation (ETF), 2005.

${ }^{6}$ Central Bank of Jordan (2016): Financial Stability Report 2015.

${ }^{7}$ Central Bank of Jordan 2015, Financial Stability Report, Jordan, viewed July 2017

${ }^{8}$ Central Bank of Jordan (2016): Financial Stability Report 2015.

${ }^{9}$ Central Bank of Jordan (2016): Financial Stability Report 2015.

${ }^{10}$ Central Bank of Jordan Bylaw no. 5/2015
} 
countries to reduce the burden thrown on governments, to engage members of societies in matters of development, and to stimulate and encourage the private sector to take more responsibility in social development. AGFUND wants this to be achieved through: micro-loans, savings, and insurance. AGFUND is confident that providing these financial services will help combating poverty and will alleviate its impact on developing communities. It will also help raising the living standards of the poor so they become self-reliant, more creative, and productive. To sum up, AGFUND's main objective of creating a microfinance bank is to provide financial inclusion for poor people ${ }^{11}$. In perusal of this vision, the AGFUND has established banks in nine (9) countries; Jordan: National Microfinance Bank (2006), Yemen: Al - Amal Microfinance Bank (2008), Bahrain: Ibda'a Microfinance Bank (2009), Syria: Ibda'a Microfinance Bank (2011), Sierra Leone: The Bank for Innovation and Partnership (2011), Lebanon: Ibda'a Microfinance Company (2012), Sudan: Ibda'a Microfinance Bank (2013), Palestine: Ibda'a Microfinance Company (2014) and Mauritania: Ibda'a Microfinance Bank (2015).

The AGFUND model argues that microfinance needs to be combined with other actions to effectively improve the living conditions of its beneficiaries. Under this model, AGFUND Microfinance Institutions provide beneficiaries with numerous financing programs and channels along with non-financing services aimed at capacity building for targeted groups to ensure success of their projects and grow them from microenterprises into small and medium sized enterprises. To institutionalize the complementarities between financing and non-financing services, the "AGFUND Link Program" has been established. This program seeks complementarities between financing and non-financing services by implanting them in a hybrid product to be provided to borrowers. The purpose of this paper is to describe and evaluate the methodology of "AGFUND's Link Program", i.e., a process which the owners of micro-enterprises can undergo to help them grow their micro-enterprises into small and medium sized enterprises.

\section{Literature Review}

Vertical growth studies illustrated that many Micro and Small Enterprises do not usually grow as it would be expected. These enterprises tend to be stable and remain within their establishment size categories (Kibas, 1995). In particular cases, several papers have indicated that $50 \%$ and $60 \%$ of existing Micro and Small Enterprises in Asia and Latin America grew from micro to small and medium enterprises (Kibas, 1995). Furthermore, Gudda (2003) have studied the market in Nigeria and found that few projects grew naturally from micro into small and medium enterprises; only 43.7\%. Moving to other African countries, results indicated that the situation is even worse; only $10.75 \%$ enterprises grew in Rwanda and only $20.7 \%$ grew in Botswana (Mwaniki, 2006). Finally, the growth of micro and small projects into big ones in Kenya is very low as well. Only four companies graduated from Small and Medium Enterprises category in 2009; this represents $4 \%$ only (Muiruri, 2014). Turning to India, the MSE sector played a crucial role in the overall industrial economy. The sector constitutes 39\% of the manufacturing production and 33\% of the total export (Graham, 2000).

To highlight the role of financial and non-financial services in supporting MSE sector, the outreach of MFIs in Kenya is constrained despite their growing number, especially in rural areas. The main reason behind this dilemma is the limited resource base of these institutions and lack of institutional capacity to provide a numerous financing programs (GOK, 2005). These results provided clear evidence of the importance of the non-financial services in supporting MSE. Dikki et al. (2014) assessed the impact of non-financing services of MFIs on the performance of women entrepreneurs in Nigeria. They reached to a result that the non- financial support of MFIs did not have any significant impact on the performance of female entrepreneurs, except in the area of training which had a significant impact on income level and asset acquisition. This means that there is a positive significant relationship between training on the one hand and income and assets of entrepreneurs on the other (Muneer et al., 2017).

The impact of financial and non-financial support on the efficiency of small enterprises in Nigeria was studied by Fasoranti et al. (2006). The aim was to identify the technical and management efficiency of small business owners to be influenced by human capital variables (education level, age, and work experience) and

${ }^{11}$ www.agfund.org 
institutional/socioeconomic variables (loan interest, loan size, follow up with lender, and training programs). Staying in Nigeria, Ogunrinola and Alege (2007) employ non-financial services such as pre-lending training, cross guarantee-ship and group membership along with financial services, and found that microfinance institutions to influence positively the micro enterprises owners in the remote areas of Nigeria. It is indicated that 42 of the businesses which took loans reported business success as a result of receiving financing services. Furthermore, the business owners accomplished a very high loan repayment rate of $96 \%$ and a reduction in the rate of business failure. The study confirmed that pre non-financial services had positive impact on microenterprise development in Nigeria.

\section{Methodology}

We have developed the following process to identify candidates (MSE) from the AGFUND Microfinance Institutions/Banks which have the potential to grow. Based on this, the methodology will be as follows:

Review and evaluate the exiting MFIs/banks portfolios of micro-enterprises against the following criteria:

- Formal or informal businesses (Whether registered or not);

- Sustainable increase of business profits as a result of activities expansion,

- Ability to create job opportunities which will contribute to reducing unemployment,

- Improvement in marketing and sales

- Benefit from the health insurance services (if any)

- The owner of micro-enterprise business in terms of credibility with the:
$\checkmark \quad$ Microfinance Bank
$\checkmark \quad$ The market
$\checkmark \quad$ His/her Clients

Based on the above, AGFUND and the Microfinance Bank will select the first group of micro-enterprise owners for financial and non-financial assistance, to help grow micro-enterprises into small and medium enterprises. Branch managers and loan officers will make significant contribution to identify microenterprises which have the potential to grow. In additions, loan officers will be consulted as they know the details of the projects they continuously follow up and visit.

Review, modify and validate with the selected micro-enterprises' owners what opportunities they have identified and how they intend to grow their businesses. Usually, the micro business owners are realizing their needs and aware of what their projects lack. They are the ones who run day-to-day operations; accordingly, they know the details of their projects and what type of support and intervention are most needed.

Based on this, AGFUND and the MFI/bank will define developmental goals with the MSE in terms of what is required to achieve the desired growth. This will cover improvement in terms of:

- Sales

- Marketing

- Profitability

- Expansion and job creation

$>$ Once the needs are identified, AGFUND and the MFI/Bank will determine what types of support and interventions will appropriately address the identified needs. This support should be based on best cultivation practices, which help ensure the success of value-addition activities. AGFUND will not impose its ideas or provide direct advice to the micro business owners.

> AGFUND will apply a custom-tailored approach, reaching out to MSE owners and helping them to improve their business.

$>$ In addition, AGFUND will focus on Group Counseling; as this method is considered the most effective and least costly way of creating growth and change in business. In the group counseling, there will be many opportunities for every micro business owner to share their thoughts, ideas, and discuss the challenges and obstacles they usually face. AGFUND will try to form groups who are in the same sector and their 
activities complement each other in order for discussions to be industry focused. Groups can meet once monthly, but sometimes more often. The idea and support of group counseling is an enriching experience. The group counseling should lead at some stage to create linkages or maybe mergers among the micro business owners.

$>$ When the aggregate and singular interventions are identified, AGFUND and the MFI/Bank will set a plan for execution of the interventions. They will also work on identifying general desired outputs/impacts for the interventions before implementing them.

$>$ AGFUND and microfinance bank will execute the identified interventions with MSE owners according to a set schedule.

$>$ MSE will be monitored after interventions are delivered against the predefined desired outputs/impacts. This would be recorded and reported and would provide the basis for additional improvements to the AGFUND Link Program process.

Figure 1: Steps provisioning throughout the life-cycle of the Link Program

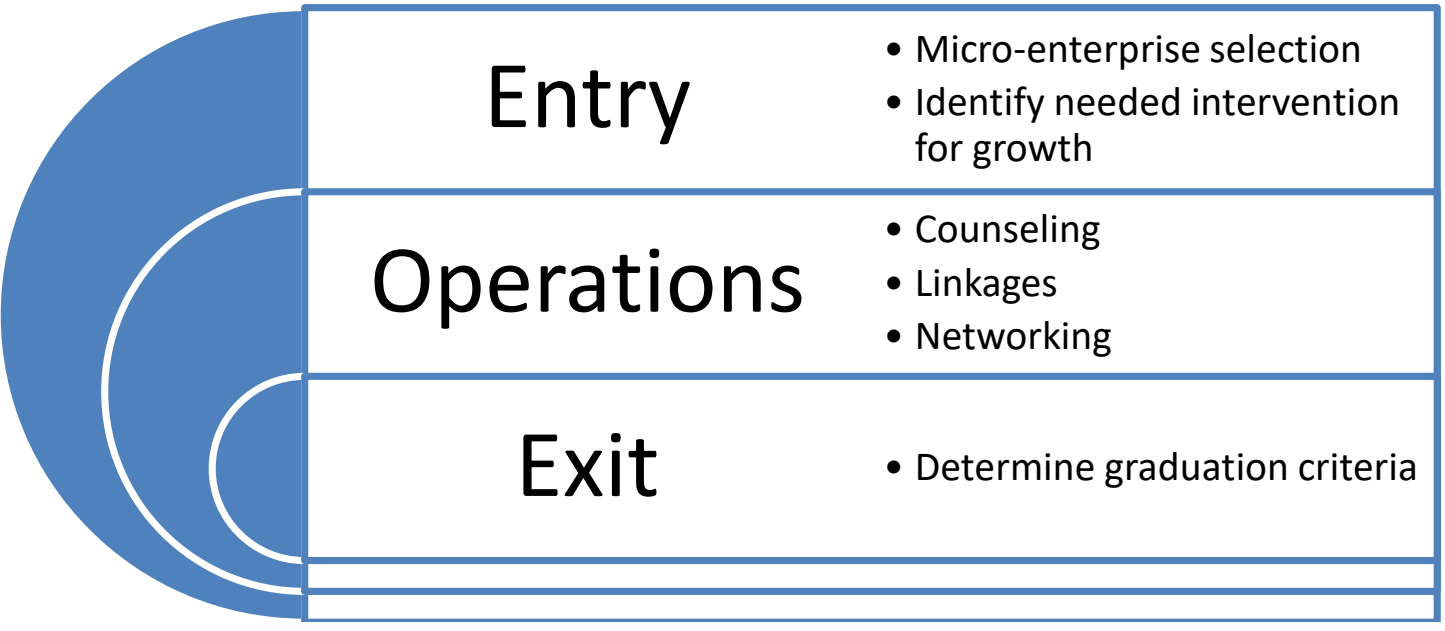

Figure 2: Operations Process

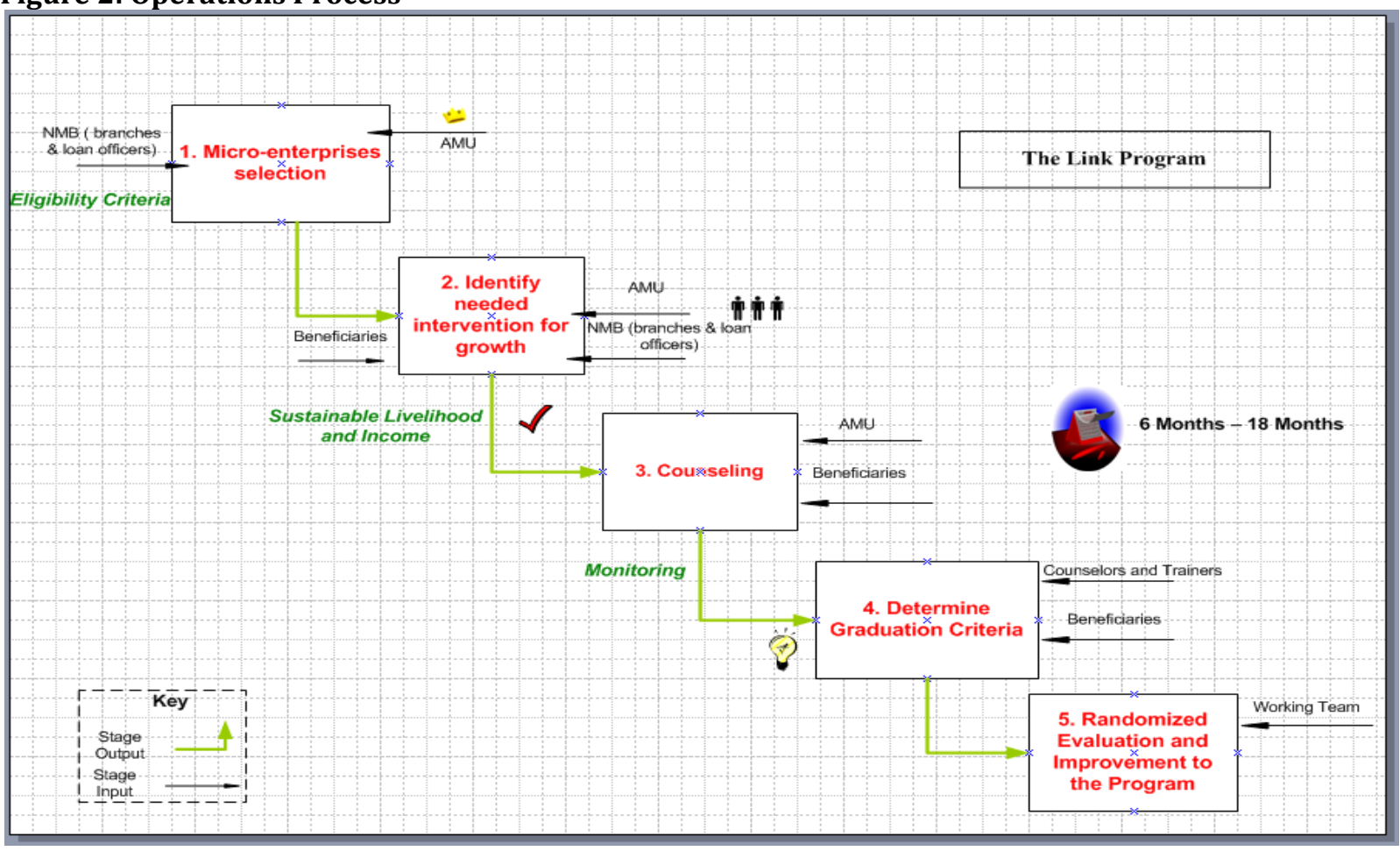




\section{Results}

Applying the "Link Program" on the NMB in Jordan has revealed interesting results. When we reviewed and evaluated the exiting NMB portfolio of micro-enterprises; we found $8000^{12}$ clients out of 56000 clients who own productive micro-enterprises and took productive loans. Focusing on the process already implemented by the NMB in supporting enterprises to move from micro to small and medium, the "AS IS" situation as to the non - financial services in the NMB includes the following services:

- Counseling by loan officers,

- Networking,

These existing "AS IS" non - financial services have led to the graduation of 1095 clients during 6 - 18 months; only $13.7 \%$ of clients of NMB who took business loans. The sectoral distribution of the graduated projects is shown in figure (3).

\section{Figure 3: Sectoral distribution of the NMB graduated projects}

\section{Sectoral Distribution}

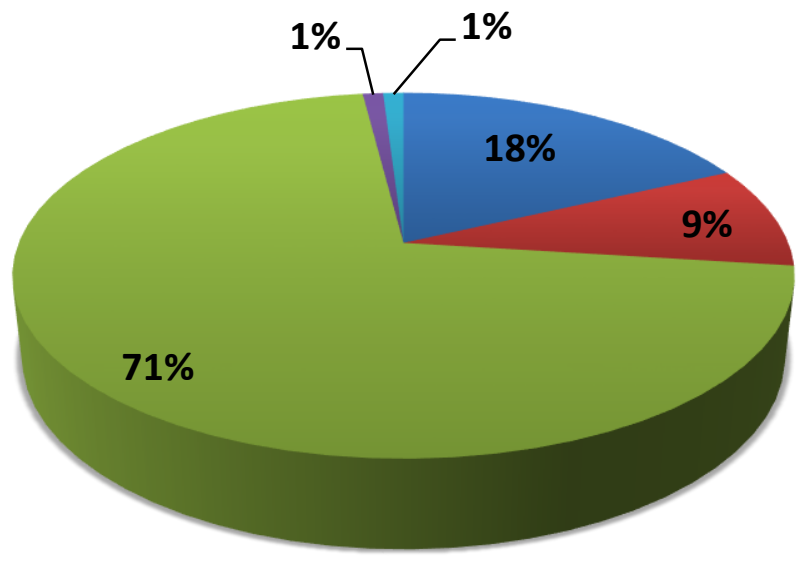

Service Sector

Industrial Sector

Trade Sector

Agricultural Sector

Tourism Sector

The improvements in terms of things in these projects during 6-18 months are the followings:

- Finishing 3 loan periods with outstanding credibility and dedication of re-payment $(\$ 3000, \$ 5000$, more than $\$ 10,000)$.

- Sustainable growth rate of income achieved as a result of activities development; the growth rate reached $10 \%-45 \%$ based on the sector.

- Formalizing the enterprise by registering it with the government.

- Generating jobs for local candidates. The graduated projects provided 1,749 job opportunities.

- Benefiting from the health insurance services provided by NMB

\section{Design: Baselines \& Targets}

$>$ Baselines: AS-IS situation before implementing changes

Targets: Results to Be reached (in the short/medium/long terms)

\section{Three Stage Approach to the Link Program:}

A. Analyses: The purpose of this phase is to understand the "AS IS" environment in the field of nonfinancial services within the AGFUND MFIs/Banks, to establish baseline and discuss with the crucial

\footnotetext{
12 The NMB has more than 8000 clients who obtained loans for production purposes; however, we selected clients who are eligible for entering the LINK program.
} 
stakeholders in which direction should the non-financial services environment be reformed. We will map the services that have been used for moving several enterprises from micro to small and medium.

B. Modeling and Recommendation: The goal of this phase is to deliver clear direction about future improvement with specific implementation scenario, outlining the necessary support that best fit the microenterprises, and to make AGFUND and the relevant stakeholders aware about their future impact.

C. Acceptance: The goal of this phase is to obtain acceptance of the new approach by all the relevant stakeholders and be ready for further implementation.

Table 1: Display the design and target

\begin{tabular}{ll}
\hline Phase & Deliverable \\
\hline Analyses & Baseline: Analyses of the “AS IS" situation as to the non - financial \\
& services in the AGFUND Banks, process mapping. Focusing on the process \\
& already implemented in supporting enterprises to move from micro to \\
& small and medium.
\end{tabular}

Modeling and Target: Modeling and recommendation of the future "TO BE" Process of Recommendation non - financial services from a policy, personal, marketing, investment and business structure aspect.

Acceptance Final: Compilation of all the findings related to the non - financial service road map, endorsement by all stakeholders, commitment to embark into the new service.

\section{Figure 4: Concept Map of "To Be" Scenario}

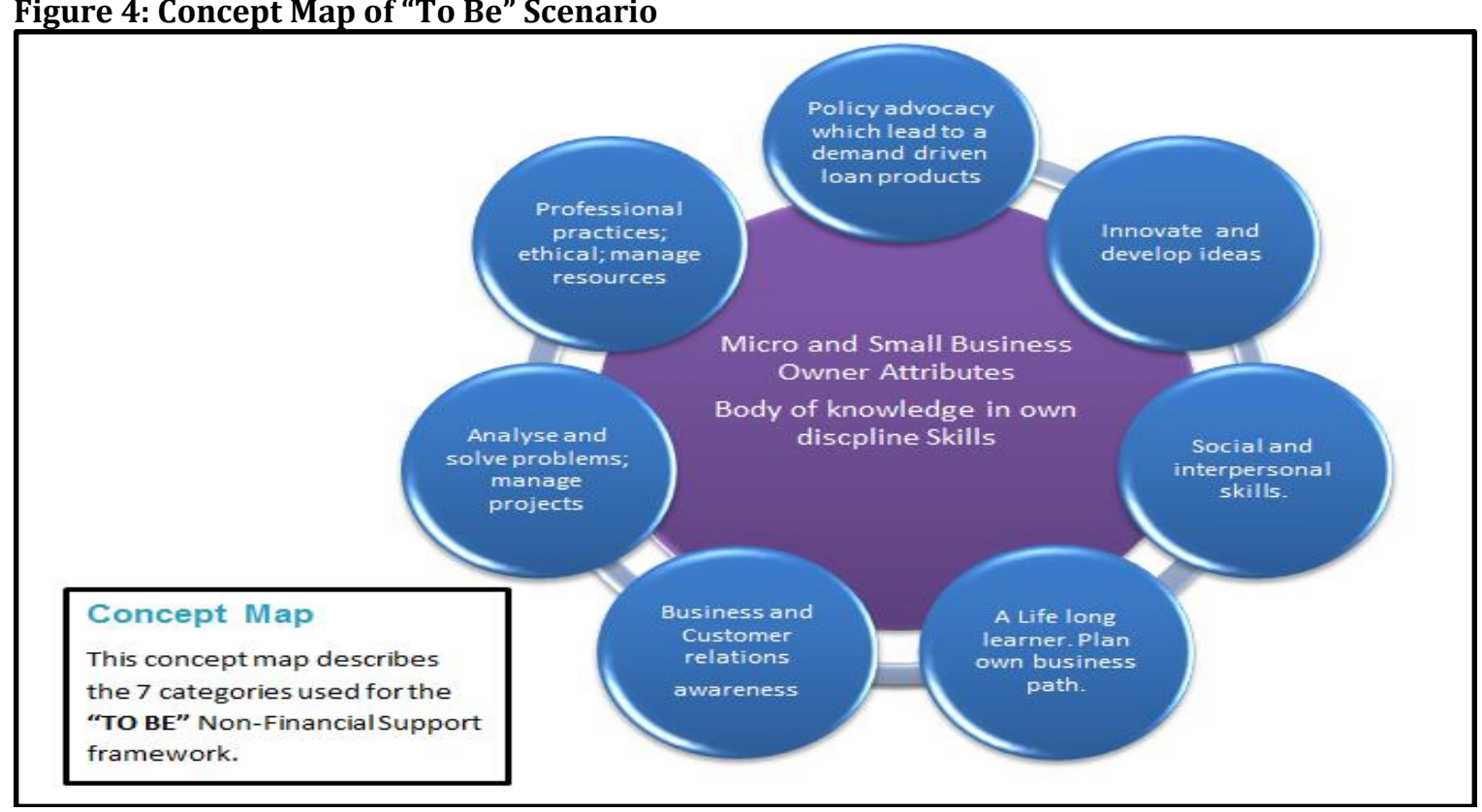

\section{Conclusion}

This study assessed the impact of non-financial service intervention of the NMB on the performance of MSE entrepreneurs in Jordan. Certain eligibility criteria were established to select MSE entrepreneurs from the NMB database. From the findings of this study, it was concluded that the non-financing services of NMB did have a significant impact on the performance of MSE entrepreneurs. However, few projects grew from micro to small and medium sized enterprises as a result of the existing "AS IS" non - financial services provided by the NMB, as they represent only $13.7 \%$ of clients of NMB who took business loans. Although many micro and 
small enterprises do not usually grow as it would be expected, the result from Jordan is below the level of international practices which showed that $50 \%$ to $60 \%$ of modern MSEs in Latin America and Asia grew from low entrepreneurs. Furthermore, African countries such as Nigeria have shown similar results as enterprises which grew naturally from micro to small level at $43.7 \%$ in this country. However, the case of Jordan is similar to other low-income African countries such as Botswana (20\%) and Rwanda (11\%).Based on these results, it is concluded that startup business owners seem to be inadequately prepared, and lack the proper entrepreneurial skills and attitudes that are needed to successfully start an enterprise, to run it in the market and to allow it to grow. Therefore, the building block of an NMB business strategy would be the design and delivery of a more innovative and comprehensive financing and non-financing service to an NMB's clients; i.e., "TO BE" approach. Every non-financing service-professional service, training, and policy advocacy—should be designed to obtain the greater goal of supporting customers in strategically selecting, starting and growing their enterprises. Finally, the MFIs should change their policy in targeting clients; supporting business startups in vocational education through targeting female and male vocational graduates will improve the pathways to the labor market for youth.

\section{References}

Central Bank of Jordan. (2015). Financial Stability Report, Jordan, viewed July 2017 at http://www.cbj.gov.jo/EchoBusV3.0/SystemAssets/PDFs/EN/FINANCIAL\%20STABILITY\%20REPO RT\%202015.pdf.

Dikki, A., Bayero, M. \& Dogarawa, A. (2014). Impact of Non-Financial Services of Microfinance Banks (MFBs)on the Performance of Women Entrepreneurs in Nigeria. European Journal of Business and Management, 6(34), 158-163.

Fasoranti, M., Akinrinola, O. \& Ajibefun, A. (2006). Impact of microcredit and training on efficiency of small scale entrepreneurs: Evidence from National Directorate of Employment (NDE) loan/training programs in Nigeria. The Social Sciences, 1(4), 264-269.

Government of Kenya. (2005). Development of MSE for Wealth and employment creation of poverty reduction Government printer, Nairobi, viewed July 2017 at https://searchworks.stanford.edu/view/6369093, sessional paper no.2.

Gudda, P. (2003). Saving mobilization among MSE in Kisumu. Paper presented at first international conference on entrepreneurship and capacity building in Globalize Economy USIU, A, Nairobi.

Graham, R. (2000). How Big Are the Tax Benefits of Debt?', The Journal of Finance, 55(5), 1901-1942.

International Labor Organization 2011. The International Financial Crisis and the Labor Market: A Review of the Impact and Policy Responses, Geneva, viewed July, 2017.

Kibas, P. (1995). Impact of credit on micro- enterprise development in Kenya. Unpublished PhD Thesis. University of Illinois Urbana-Champaign.

Mwaniki, R. (2006). Study on the Role of financial institutions in poverty reduction - Integrating financial services in poverty reduction strategies, Kenya, Act Press.

Muiruri, P. (2014). The Role of Micro-Finance Institutions to the Growth of Micro and Small Enterprises (MSE) in Thika, Kenya. International Journal of Academic Research in Accounting, Finance and Management Sciences, 4(4), 249-262.

Muneer, S., Ahmad, R. A. \& Ali, A. (2017). Impact of Financial Management Practices on SMEs Profitability with Moderating Role of Agency Cost. Information Management and Business Review, 9(1), 23-30

Ogunrinola, I. \& Alege, O. (2007). Microcredit and microenterprise development: An analysis of some rural based enterprises in Nigeria. Nigeria Journal of Economics and Social Studies, 49(1), 95-113.

The European Training Foundation (ETF). (2005). Unemployment in Jordan, Austria, viewed July 2017. 